\title{
Appropriate use of chemical indicators in the steam sterilization process: Assured sterility and economy
}

\author{
Debabrata Basu MSc, DHM
}

Tata Medical Center, Kolkata, India

To the Editor - Satisfactory quality monitoring of sterilization processes is of paramount importance in maintaining the reliability of sterile supplies to caregivers. The quality monitoring process of each sterilization technique depends on chemical, biological, and physical parameters, according to the recommendations of the Association for the Advancement of Medical Instrumentation (AAMI), the International Standards Organization (ISO), and the European Norms (EN). ${ }^{1}$ The chemical monitoring system is composed of a set of indicators based on specific requirements: exposure monitoring (exposure control tape, type I), equipment monitoring (BowieDick test pack, type II), and package monitoring (internal chemical indicators, types III and VI). All chemical indicators are tested in a chemical indicator evaluation resistometer (CIER vessel) according to the ISO 11140-1 standard. A validated chemical indicator can easily detect steam quality, noncondensable gases, and proper steam penetration inside the sterilizer. ${ }^{1}$ The biological indicator system consists of viable nonpathogenic microorganisms, providing a defined resistance to a specified sterilization process. The biological indicators are prepared using a live bacterial spore containing a minimum of 1 million colony-forming units (CFU).

Biological indicators provide a direct measure of lethality. They are approved by the American Type Culture Collection (ATCC) and are also tested using the biological indicator evaluation resistometer (BIER vessel) according to ISO $11139 .^{2}$ All chemical and biological indicators are called process challenge devices (PCDs); they are used as a medical device simulator (MDSs) for sterility assurance. The physical monitoring system consists of all critical parameters: sterilization time, temperature, pressure, and saturated steam. The sterilization process for those physical monitoring systems has been standardized with a digital microprocessor or analog meter for real-time monitoring of the steam generator, door gasket, chamber, and/or jacket, which continuously monitors all critical parameters throughout the cycle. The chemical and biological monitoring systems are depend on the same physical parameters, but they also indicate the presence of saturated steam for sterility assurance not reported using parametric release only.,4

The difficulty with the physical monitoring system is the detection of the presence of saturated steam (ie, water vapor in a state of equilibrium between condensation and evaporation) for sterility assurance because it is based on records demonstrating that the process parameters were delivered within specified tolerances (ISO/TS 11139:2006). However, the detection of only the saturated steam for sterility assurance (EN 556) but using chemical indicator in every set (ie, package monitoring) is meaningless when the

Author for correspondence: Debabrata Basu, MSc, Tata Medical Center, 14 Major Arterial Road (E-W), New Town, Rajarhat, Kolkata 700160 India. Email: debabrata. basu@tmckolkata.com

Cite this article: Basu D. (2019). Appropriate use of chemical indicators in the steam sterilization process: Assured sterility and economy. Infection Control \& Hospital Epidemiology, 40: 831-832, https://doi.org/10.1017/ice.2019.126 sterilizer is under routine monitoring and control according to EN ISO 14937 or is validated by a third party according to EN ISO17665-1..$^{5}$ Although a process indicator (type I) is required to ensure that the goods have already been exposed to a sterilization process, this indicator does not provide any information about the efficacy of the sterilization process.

In general, the steam sterilization process depends on deep vacuum and proper steam penetration system. This can only be achieved by good vacuum pump, proper steam injection, rejection of noncondensable gases, saturated steam, and proper load configuration. ${ }^{6}$

According to the routine monitoring protocol, the sterilizer should run with diagnostic cycle first (ie, maximum leakage should be below $1.3 \mathrm{kpa}$ as per EN 285) followed by an air removal test using a Bowie-Dick test pack (EN 285, part 17). If both cycles are passed satisfactorily, then a biological cycle should run for biological monitoring. The PCDs are kept in the most critical area of a sterilizer for the worst-case scenario (ie, lowest acceptable temperature or shortest acceptable exposure time). Thus, if a single Bowie-Dick or a biological indicator can monitor the entire load for sterility assurance, then there is no reason to keep an internal chemical indicator in every set. However, a normal PCD (ie, a dummy pack containing a type V or VI chemical indicator for surface sterilization purposes) does not assure the sterility of luminal or complex instruments because these instruments are more challenging with regard to air entrapment. To avoid these potential problems, a hollow-processchallenged device by Helix PCD (HPCD, according to EN 867-5 and EN 285) is used to simulate the luminal instruments by measuring their inner surfaces (ie, surface measurement by inner diameter $\times$ inner length with wall thickness and material of tubes). The indicator in the HPCD is a type II chemical indicator (EN ISO 11140-1) for detecting the noncondensable gases in every cycle. ${ }^{1,8}$

In our 200-bed cancer center in eastern India, $>200$ surgical sets (minor and major sets) are packed every day, and 5 instrument cycles are run per day to sterilize them. We have provided a cost calculation (Table 1) as a reference; it shows a clear cost difference in between not using an internal chemical indicator versus using an internal chemical indicator, increases the cost of sterilized sets. ${ }^{1}$

According to the international standard, all type V or VI indicators are called 'integrating' or 'emulating' indicators, and they can only specify the constant concentration of steam with time and temperature. Only those indicators have defined sated value (SV) according to EN ISO 11140-1. Moreover, if an HPCD with a type II chemical indicator monitoring air removal, temperature-time-integral ( $F_{0}$ value) and condensation of steam to water is added to the type $\mathrm{V}$ or VI chemical indicator (as a dummy pack) in every cycle, then this monitoring is a better alternative to releasing the sterile load than including the internal chemical indicator in every set. Ensuring quality in sterilization processes requires considerable. The challenge is to ensure that the sterilization indicators are used efficiently to prevent waste and maintain quality. ${ }^{9}$ 
Table 1. Cost Differnce With or Without Internal Chemical Indicator Used in Every Set

\begin{tabular}{|c|c|c|c|c|c|c|c|}
\hline $\begin{array}{l}\text { Cost With Internal } \\
\text { Chemical Indicator }\end{array}$ & $\begin{array}{l}\text { Cost per Piece } \\
\text { (INR) }\end{array}$ & $\begin{array}{l}\text { Cost per Day } \\
\text { (INR) }\end{array}$ & $\begin{array}{l}\text { Cost per Year } \\
\text { (INR) }\end{array}$ & $\begin{array}{l}\text { Cost Without Internal Chemical } \\
\text { Indicator }\end{array}$ & $\begin{array}{l}\text { Cost per Piece } \\
\text { (INR) }\end{array}$ & $\begin{array}{l}\text { Cost per Day } \\
\text { (INR) }\end{array}$ & $\begin{array}{l}\text { Cost per Year } \\
\quad \text { (INR) }\end{array}$ \\
\hline $\begin{array}{l}\text { Bowie-Dick test Pack } \\
\text { (1 per cycle) }\end{array}$ & $\begin{array}{l}\text { Rs. } 500 \\
\$ 7.69\end{array}$ & $\begin{array}{l}\text { Rs. } 500 \\
\$ 7.69\end{array}$ & $\begin{array}{l}\text { Rs } 180000 \\
\$ 276.92\end{array}$ & Bowie-Dick test pack & $\begin{array}{l}\text { Rs. } 500 \\
\$ 7.69\end{array}$ & $\begin{array}{l}\text { Rs. } 500 \\
\$ 7.69\end{array}$ & $\begin{array}{l}\text { Rs. } 180,000 \\
\$ 276.92\end{array}$ \\
\hline Expose control tape & $\begin{array}{l}\text { Rs. } 450 \\
\$ 6.92\end{array}$ & $\begin{array}{l}\text { Rs. } 450 \\
\$ 6.92\end{array}$ & $\begin{array}{l}\text { Rs. } 162,000 \\
\$ 2492.30\end{array}$ & Expose control tape & $\begin{array}{l}\text { Rs. } 450 \\
\$ 6.92\end{array}$ & $\begin{array}{l}\text { Rs. } 450 \\
\$ 6.92\end{array}$ & $\begin{array}{l}\text { Rs. } 162000 \\
\$ 2492.30\end{array}$ \\
\hline Batch label & $\begin{array}{l}\text { Rs. } 1 \\
\$ 0.01 \\
\end{array}$ & $\begin{array}{l}\text { Rs. } 200 \\
\$ 3.07\end{array}$ & $\begin{array}{l}\text { Rs. } 72,000 \\
\$ 1107.69 \\
\end{array}$ & Batch label & $\begin{array}{l}\text { Rs. } 1 \\
\$ 0.01\end{array}$ & $\begin{array}{l}\text { Rs. } 200 \\
\$ 3.07\end{array}$ & $\begin{array}{l}\text { Rs. } 72000 \\
\$ 1107.69 \\
\end{array}$ \\
\hline $\begin{array}{l}\text { Internal chemical } \\
\text { indicator } \\
\text { (every set) }\end{array}$ & $\begin{array}{l}\text { Rs. } 15 \\
\$ 0.23\end{array}$ & $\begin{array}{l}\text { Rs. } 3,000 \\
\$ 46.15\end{array}$ & $\begin{array}{l}\text { Rs. } 1,080,000 \\
\$ 16,615.38\end{array}$ & $\begin{array}{l}\text { Batch monitoring by HPCD } \\
\text { (every load) }\end{array}$ & $\begin{array}{l}\text { Rs. } 60 \\
\$ 0.92\end{array}$ & $\begin{array}{l}\text { Rs. } 300 \\
\$ 4.61\end{array}$ & $\begin{array}{l}\text { Rs. } 108,000 \\
\$ 1,661.53\end{array}$ \\
\hline $\begin{array}{l}\text { Total cost with chemica } \\
\text { indicator in a year }\end{array}$ & & $\begin{array}{l}\text { Rs. } 4295 \\
\$ 66.07\end{array}$ & $\begin{array}{l}\text { Rs. } 1,546,200 \\
\$ 23,787.69\end{array}$ & Total cost without chemical indic & ator in a year & $\begin{array}{l}\text { Rs. } 1595 \\
\$ 24.53\end{array}$ & $\begin{array}{l}\text { Rs. } 574200 \\
\$ 8,833.84\end{array}$ \\
\hline
\end{tabular}

Note. Cost difference in INR per year: Rs. $1,546,200-$ Rs. $574,200=$ Rs. 972,000 . Cost difference in USD per year: $\$ 23,787.69-\$ 8,833.84=\$ 14,953.85$.

\section{Acknowledgments. None.}

Financial support. No financial support was provided relevant to this article.

Conflicts of interest. All authors report no conflicts of interest relevant to this article.

\section{References}

1. Ling ML, Ching P, Widitaputra A, Stewart A, Sirijindadirat N, Thu LTA. APSIC guidelines for disinfection and sterilization of instruments in health care facilities. Antimicrob Resist Infect Control 2018;7:25. doi: 10.1186/ s13756-018-0308-2.

2. Gillis JR. Biological indicators for steam sterilization process monitoring. Bull Parenter Drug Assoc 1975;29:111-121.

3. van Doornmalen J, Kopinga K. Review of surface steam sterilization for validation purposes. Am J Infect Control 2008;36:86-92.

4. Swenson D, Wilder JA, Hancock CO. Steam sterilization validation for implementation of parametric release at a healthcare facility. Biomed Instrum Technol 2010;44:166-174.
5. Shintani H. Validation study and routine control monitoring of moist heat sterilization procedures. Biocontrol Sci 2012;17:57-67.

6. Nagpal AK, Shriniwas AK. Principles of steam sterilization. Health Popul Perspect Issue 1978;1:40-50.

7. Basu D, Bhattacharya S, Mahajan A, Ramanan V, Chandy M. Sterilization indicators in central sterile supply department: quality assurance and cost implications. Infect Control Hosp Epidemiol 2015;36:484-486.

8. Requirements on the hollow load helix-PCD system according to EN 867-5. gke website. https://www.gke.eu/en/helix-pcd-testset-steam-ci. html?file=files/gke_2013/content/en/downloads/Technical\%20information/ Chemical\%20Indicators/091\%20Requirements\%20hollow\%20load\%20helix \%20system.pdf. Published 2013. Accessed April 4, 2019.

9. Value of chemical indicators and PCDs for the monitoring of steam sterilization processes. gke website. https:/www.gke.eu/es/lawsregulationses.html?file=files/gke_2013/content/en/downloads/Laws\%20and\%20Regula tions/Guidelines\%20and\%20Recommendations/Value\%20of\%20Chemical \%20Indicators $\% 20$ and\%20PCDs\%20for\%20the\%20Monitoring\%20of\%20 Steam\%20Sterilization\%20Processes.pdf. Published 2013. Accessed April 4, 2019.

\title{
Assessment of stool color in Clostridioides difficile infection: A pilot study
}

\author{
Hiroshi Sugimoto $\mathrm{MD}^{1}(\mathbb{1})$, Kuniyoshi Hayashi $\mathrm{PhD}^{2}$, Keitaro Furukawa $\mathrm{MD}^{1}$ and Nobuyoshi Mori MD \\ ${ }^{1}$ Department of Infectious Diseases, St Luke's International Hospital, Tokyo, Japan and ${ }^{2}$ Graduate School of Public Health, St Luke's International University, \\ Tokyo, Japan
}

To the Editor-Clostridioides difficile, formerly known as Clostridium difficile, is a spore-forming anaerobe that is believed to colonize $\sim 5 \%-10 \%$ of healthy adults and is usually asymptomatic. ${ }^{1}$ The toxin-producing strains of Clostridioides difficile can cause Clostridioides difficile infection (CDI), which is characterized by frequent diarrhea. CDI is the leading cause of infectious diarrhea

Author for correspondence: Hiroshi Sugimoto, Email: dr.sugimoto@gmail.com

Cite this article: Sugimoto H, et al. (2019). Assessment of stool color in Clostridioides difficile infection: A pilot study. Infection Control \& Hospital Epidemiology, 40: 832-833, https://doi.org/10.1017/ice.2019.125 in hospitalized patients, and some risk factors of CDI, such as old age, antibiotic use, and proton pump inhibitor (PPI) use have already been reported. ${ }^{2,3}$ The incidence of CDI is $0.8-4.71$ per 10,000 patient days in Japan. ${ }^{4}$ Clostridioides difficile can be widely distributed in the environment as spores, which are extremely resistant to environmental changes including alcohol sterilization; therefore, prompt and appropriate diagnosis of CDI is important for the prevention of nosocomial spread of CDI.

A rapid stool test kit for detecting toxins and glutamate dehydrogenase $(\mathrm{GDH})$ antigen is generally used to diagnose CDI. 